\title{
Synthesis of Water-Soluble Polymeric Prodrugs Possessing 4-Methylcatechol Derivatives by Mechanochemical Solid-State Copolymerization and Nature of Drug Release
}

\author{
Shin-ichi Kondo, ${ }^{*}, a$ Yasushi SASAI, ${ }^{a}$ Masayuki KUZuYA, ${ }^{a}$ and Shoei FuruKaWA ${ }^{b}$ \\ ${ }^{a}$ Laboratory of Pharmaceutical Physical Chemistry, Gifu Pharmaceutical University; and ${ }^{b}$ Laboratory of Molecular \\ Biology, Gifu Pharmaceutical University; 5-6-1 Mitahora-Higashi, Gifu 502-8585, Japan. \\ Received April 15, 2002; accepted September 6, 2002
}

In this study we synthesized the water-soluble polymeric prodrugs possessing a 4-methylcatechol (4MC) derivative as a side chain by mechanochemical solid-state copolymerization. 1-Benzoyl-4-methylcatechol (Bz4MC) was selected as a model compound of $4 \mathrm{MC}$, and its methacryloyl derivative (1) was synthesized. 6-O-Methacryloyl-D-galactose (2) was also prepared as a water-soluble monomer. The mechanochemical solid-state copolymerization of 1 and 2 was carried out to obtain the water-soluble polymeric prodrug possessing the Bz4MC as a side chain. The mechanochemical copolymerization of 1 and 2 proceeded to completion, and the polymeric prodrug produced possessed a narrow molecular weight distribution. Three kinds of polymeric prodrugs, whose compositions were different from one another, were hydrolyzed in vitro. The hydrolysis of these polymeric prodrugs proceeded to completion. The rate constants of hydrolysis decreased with increasing the mole fraction of 1 in polymeric prodrug. It was suggested that the rate constant of hydrolysis could be controlled by the composition, the mole fraction of 1 in the polymeric prodrug.

Key words mechanochemical polymerization; polymeric prodrug; nerve growth factor (NGF); 4-methylcatechol; sustained release

Although evidence indicates that nerve growth factor (NGF) may have promise as a therapeutic agent for neurodegenerative diseases like Alzheimer's, ${ }^{1,2}$ its potential use in such a central nervous system (CNS) disorder is prevented by its inability to cross the blood-brain barrier (BBB). A variety of low molecular weight compounds has been found as a NGF stimulator. ${ }^{3-9)}$ Among them, 4-methylcatechol (4MC) is a potent NGF stimulator both in vivo ${ }^{10,11)}$ and in vitro. ${ }^{12-14)}$ 4MC, however, could not penetrate into the brain for lacking sufficient lipophilicity. Several dihydropyridine derivatives of $4 \mathrm{MC}$ were synthesized as a potential brain selective targetry forms by Kourounakis et al. ${ }^{15)}$ to increase the lipophilicity and the BBB permeability of 4MC.

Major advancements have been made in the understanding of Alzheimer's disease. It has been suggested that the integrity of BBB may be compromised in Alzheimer's disease. ${ }^{16,17)}$ Immunohistological studies have demonstrated the presence of serum proteins in the cerebrovascular amyloid in Alzheimer's patients suggesting abnormal BBB permeability. ${ }^{18-20)}$ Therefore, it is expected that the polymeric prodrugs, which possess $4 \mathrm{MC}$ or its derivative as a side chain, can passively be delivered into the diseased part of the brain in Alzheimer's patients. It is also known that $4 \mathrm{MC}$ is easily oxidized in vivo. The polymeric prodrugs possessing 4MC would be useful in terms of the stabilization and sustained release of $4 \mathrm{MC}$.

We have reported the synthesis and nature of drug release of novel polymeric prodrugs prepared by mechanochemical solid-state polymerization. ${ }^{21-33)}$ Several important conclusions were reached from a series of such studies. The monomers prepared on the basis of the structural criteria derived from quantum chemical considerations underwent facile mechanochemical solid-state polymerizations to give corresponding polymeric prodrugs essentially quantitatively. ${ }^{21,22,25)}$ Thus, this method eliminates the need for any work-up of the reaction mixture. One of the most striking properties observed in such polymers is that the resulting polymeric prodrugs are of very low heterogeneity (narrow molecular weight distribution), which is of great value in pharmaceuticals for highly functionalized polymeric prodrugs. ${ }^{22}$ It was also shown that the resulting copolymer under the appropriate experimental conditions was homogeneous in composition (ideal copolymerization). ${ }^{26)}$ Therefore, the present reactions seem to be applicable to a wide variety of vinyl monomers of an important bioactive compound with different physicochemical properties and provide a novel and simple methodology for syntheses of polymeric prodrugs through a totally dry process.

In order to gain a fundamental insight to develop a polymeric prodrug that can passively be delivered to the disease parts of brain by the peripheral administration and slowly release 4MC derivatives, we synthesized the polymeric prodrugs possessing $4 \mathrm{MC}$ derivatives as a side chain by mechanochemical solid-state polymerization. Thus, 1-benzoyl-4-methylcatechol (Bz4MC) was selected as a model compound of $4 \mathrm{MC}$ derivatives. The mechanochemical solidstate polymerization of methacryloyl derivatives of Bz4MC and water-soluble monomers, 6-O-methacryloyl-D-galactose, was carried out to obtain water-soluble polymeric prodrugs. The nature of drug release from the polymeric prodrugs formed was examined in vitro.

\section{Experimental}

Ultraviolet spectral measurements were performed with a Shimadzu Recording Spectrophotometer UV-3100 using 1-cm quartz cells. ${ }^{1} \mathrm{H}-\mathrm{NMR}$ spectra were run on a JEOL JNM-GX270 FT-NMR spectrometer using tetramethylsilane as an internal or external standard. Reading of $\mathrm{pH}$ was carried out on a TOA $\mathrm{pH}$ meter HM-16S at room temperature. Melting points were measured on a capillary melting-point apparatus and uncorrected. IR spectra were obtained on a Perkin Elmer 1650 FT-IR spectrometer. MS spectra were obtained on a JEOL JMS-SX102A mass spectrometer.

Materials Acrylamide supplied by Tokyo Kasei Kogyo Co., Ltd. (Japan) was commercially available. It was purified by recrystallization from benzene and dried in vacuo. 2-Methacryloyloxyehtyl isocyanate, Bz4MC 
and 1,2:3,4-di- $O$-isopropylidene- $\alpha$-D-galactopyranose were synthesized according to the literatures, ${ }^{31,34,35)}$ respectively.

1-Benzoyl-2-methacryloyloxyethylcarbamoyl-4-methylcatechol (1) 2Methacryloyloxyethylisocyanate $(0.40 \mathrm{~g}, 2.6 \mathrm{mmol})$ was added to a solution of Bz4MC $(0.50 \mathrm{~g}, 2.2 \mathrm{mmol})$ and triethylamine $(0.26 \mathrm{~g}, 2.6 \mathrm{mmol})$ in dry acetonitrile $(15 \mathrm{ml})$. The reaction mixture was stirred at room temperature overnight. The reaction mixture was filtered and evaporated in vacuo. The residue was dissolved in $\mathrm{CHCl}_{3}(30 \mathrm{ml})$. The $\mathrm{CHCl}_{3}$ solution was washed fully with $\mathrm{H}_{2} \mathrm{O}$, dried over $\mathrm{MgSO}_{4}$, and evaporated in vacuo. The residue was chromatographed over silica gel (Wakogel $\mathrm{C} 300$ ) in $\mathrm{CHCl}_{3}$ as an eluent. The eluted product was further recrystallized from cyclohexane and cyclohexanone $(1: 1)$ to yield $0.20 \mathrm{~g}(24 \%)$ of $1: \mathrm{mp} 69-70{ }^{\circ} \mathrm{C}$. IR $(\mathrm{KBr}) \mathrm{cm}^{-1}$ : 3315 (-CONH-), 1741, 1708 (-COO-), 1637 (vinyl group). ${ }^{1} \mathrm{H}-\mathrm{NMR}$ $\left(\mathrm{CDCl}_{3}\right) \delta: 1.88\left(3 \mathrm{H}, \mathrm{s},-\mathrm{CH}_{3}\right.$ of methacryloyl group), $2.37\left(3 \mathrm{H}, \mathrm{s},-\mathrm{CH}_{3}\right.$ of 4-methylcatechol), 3.42-3.50 (2H, m, $\left.-\mathrm{CH}_{2} \mathrm{OCO}-\right), 4.10-4.18(2 \mathrm{H}, \mathrm{m}$, $\left.-\mathrm{NHCH}_{2}-\right), 5.54(1 \mathrm{H}, \mathrm{s}$, vinyl group), $6.03(1 \mathrm{H}$, s, vinyl group), 7.05-7.17 $(3 \mathrm{H}, \mathrm{m}$, aromatic ring of 4-methylcatechol $), 7.45-7.67(3 \mathrm{H}, \mathrm{m}$, meta- and para-H of benzoyl group), $8.16-8.18$ (2H, m, ortho-H of benzoyl group). UV $\lambda_{\max }(\mathrm{EtOH}) \mathrm{nm}(\varepsilon): 230.9$ (17700). EI-MS $m / z: 383\left(\mathrm{M}^{+}\right)$. Anal. Calcd for $\mathrm{C}_{21} \mathrm{H}_{21} \mathrm{NO}_{6}$ : C, 65.79; H, 5.52; N, 3.65. Found: C, 65.65; H, 5.59; N, 3.67 .

6-O-Methacryloyl-D-galactose (2) Methacryloyl chloride (1.6 g, $15.4 \mathrm{mmol}$ ) was added to a solution of $1,2: 3,4$-di- $O$-isopropylidene- $\alpha$-Dgalactopyranose $(4.0 \mathrm{~g}, 15.4 \mathrm{mmol})$ and triethylamine $(1.6 \mathrm{~g}, 15.4 \mathrm{mmol})$ in dry acetonitrile $(60 \mathrm{ml})$. The reaction mixture was stirred at room temperature overnight. The reaction mixture was filtered and evaporated in vacuo. The residue was dissolved in $\mathrm{CHCl}_{3}(300 \mathrm{ml})$. The $\mathrm{CHCl}_{3}$ solution was washed with $\mathrm{H}_{2} \mathrm{O}$, dried over $\mathrm{MgSO}_{4}$, and evaporated in vacuo to obtain an oily substance. This oily substance $(3.0 \mathrm{~g})$ and 4-methoxyphenol $(0.15 \mathrm{~g}$, $1.2 \mathrm{mmol})$ were dissolved in formic acid $(23.75 \mathrm{ml})$ and then water $(5.9 \mathrm{ml})$ was added to the solution. The reaction mixture was stirred at $20^{\circ} \mathrm{C}$ for $20 \mathrm{~h}$. Water $(30 \mathrm{ml})$ was added to the reaction mixture. This solution was evaporated in vacuo and EtOH $(42 \mathrm{ml})$ was added to the residue. The EtOH solution was filtered and evaporated in vacuo. The residue was added to 10 times the ether. The precipitate was collected and recrystallized from EtOH to yield $0.80 \mathrm{~g}(38 \%)$ of $2: \mathrm{mp} 85-87^{\circ} \mathrm{C}$. IR $(\mathrm{KBr}) \mathrm{cm}^{-1}: 3350(-\mathrm{OH}), 1700$ (-COO-), 1640 (vinyl group). ${ }^{1} \mathrm{H}-\mathrm{NMR}\left(\mathrm{CDCl}_{3}\right) \delta: 1.88\left(3 \mathrm{H}, \mathrm{s},-\mathrm{CH}_{3}\right)$, $2.55-3.69(4 \mathrm{H}, \mathrm{br},-\mathrm{OH}), 4.14\left(2 \mathrm{H}, \mathrm{m},-\mathrm{CH}_{2}-\right), 4.37-4.94(4 \mathrm{H}, \mathrm{m}, 2,3,4$, and 5-position of galactose), $5.69(1 \mathrm{H}, \mathrm{s}$, vinyl group), $6.03(1 \mathrm{H}, \mathrm{s}$, vinyl group), $6.23\left(1 \mathrm{H}, \mathrm{m}, 1\right.$-position of galactose). EI-MS m/z: $248\left(\mathrm{M}^{+}\right)$. Anal. Calcd for $\mathrm{C}_{10} \mathrm{H}_{16} \mathrm{O}_{7} \cdot 0.5 \mathrm{H}_{2} \mathrm{O}: \mathrm{C}, 46.53 ; \mathrm{H}, 6.68$. Found: $\mathrm{C}, 46.75 ; \mathrm{H}, 6.98$.

Mechanochemical Solid-State Copolymerization A mixture of $\mathbf{1}$ and 2 was mechanically fractured under anaerobic conditions (e.g. in nitrogen) by ball milling $(6.0 \mathrm{~mm} \phi, 890 \mathrm{mg})$ in a stainless steel twin-shell blender $(7.8 \mathrm{~mm} \phi, 24 \mathrm{~mm}$ long) at room temperature for $2 \mathrm{~h}$ at $60 \mathrm{~Hz}$ according to the method previously reported. ${ }^{22}$ Residual oxygen in this system was removed with Model 1000 Oxygen Trap (Chromatography Research Supplies) coupled with Indicating Oxygen Trap (Chromatography Research Supplies). The oxygen concentration was monitored with Oxygen analyzer (Toray Engineering Co., Ltd., LC 750/PC-120) and kept below 10 ppm. Copolymerization was made on the mixture of $\mathbf{1}$ and $\mathbf{2}$ ranging in mole fraction of $\mathbf{1}$ from 0.05 to 0.5 . Mechanochemical copolymerization of $\mathbf{1}$ and acrylamide was performed in the same way as described above.

Solubility of Polymeric Prodrugs Five kinds of polymeric prodrugs, in which the mole fraction of 1 was $0.05,0.1,0.2,0.3$ and 0.4 , were used. The polymeric prodrug powder $(5.0 \mathrm{mg})$ was added to distilled water $(10 \mathrm{ml})$. The solution containing the polymeric prodrug powder was shaken for $15 \mathrm{~min}$ at room temperature. It was observed whether the polymeric prodrug powder dissolved or not.

Molecular Weight Measurement The molecular weight of polymeric prodrugs was measured with a gel permeation chromatograph (GPC; Shimadzu LC-6A) equipped with a refractive index detector (Shimadzu, RID6A), gel column (Shodex, KD-800M and KD-80M), and a data analyzer (Shimadzu, Chromatopac C-R4A), under the following conditions: elution solvent, DMF containing $10 \mathrm{mmol}$ of $\mathrm{LiBr}$; flow rate, $0.7 \mathrm{ml} / \mathrm{min}$; column temperature, $40^{\circ} \mathrm{C}$. Calibration was carried out with a standard specimen of poly(ethylene oxide).

Method of Hydrolysis The hydrolysis of polymeric prodrugs (20$25 \mathrm{mg}$ ) was conducted in the mixture of $\mathrm{pH} 7.4$ phosphate buffer $(50 \mathrm{~mm}$ $\mathrm{KH}_{2} \mathrm{PO}_{4}$ and $\left.40 \mathrm{~mm} \mathrm{NaOH}\right)(10 \mathrm{ml})$ and $\mathrm{CH}_{3} \mathrm{CN}(10 \mathrm{ml})$ at $37 \pm 0.2^{\circ} \mathrm{C}$. The $\mathrm{pH}$ of the solution unchanged before and after hydrolysis. Released $4 \mathrm{MC}$ and Bz4MC were periodically assayed by using a HPLC procedure. HPLC was performed with a Shodex Asahipak ODP-50 (4.6 i.d. $\times 250 \mathrm{~mm}$ ) and ODP-50G (4.6 i.d. $\times 10 \mathrm{~mm}$ ), and eluted with a mixture of $\mathrm{pH} 7.4$ phosphate buffer- $\mathrm{CH}_{3} \mathrm{CN}(1: 1)$ at a flow rate of $0.5 \mathrm{ml} / \mathrm{min}$.

\section{Results and Discussion}

Characterization of Polymeric Prodrugs Synthesized by Mechanochemical Solid-State Copolymerization We selected Bz4MC as a model compound of $4 \mathrm{MC}$ derivatives. 1-Benzoyl-2-methacryloyloxyethylcarbamoyl-4-methylcatechol (1) was specially synthesized as a model monomer of Bz4MC (Fig. 1). 6-O-Methacryloyl-D-galactose (2) was also prepared as a water-soluble monomer.

We carried out the mechanochemical solid-state copolymerization of $\mathbf{1}$ and $\mathbf{2}$ to obtain a polymeric prodrug, Poly $\mathbf{I}$. The mechanochemical copolymerization of $\mathbf{1}$ and acrylamide (AAm), which is a conventional water-soluble monomer, was also carried out, and Poly II was obtained (Fig. 2). The polymer conversion was determined by observing the disappearance of vinyl protons and the appearance of the corresponding alkyl protons of the polymer in the ${ }^{1} \mathrm{H}-\mathrm{NMR}$ spectra of the resultant powders (Chart 1). The mechanochemical solidstate copolymerization of these monomers proceeded to completion to give the corresponding polymeric prodrugs. This eliminates the need for any work-up such as is required in reactions in the liquid state.

We observed the behavior of dissolution of the polymeric prodrugs in water. Poly I (0.1) denotes the Poly I in which the mole fraction of $\mathbf{1}$ is 0.1 . Poly I (0.05), (0.1) and (0.2) dissolved in water at room temperature. Poly I (0.3) swelled in water but did not dissolve. Poly I (0.4) and (0.5) were also

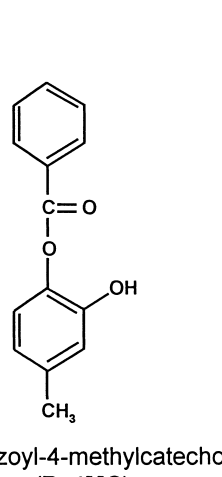

(Bz4MC)

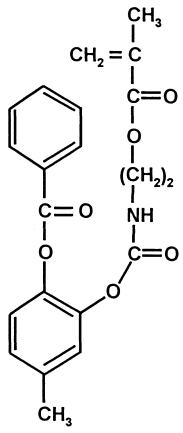

1-benzoyl-2-methacryloyloxyethyl-4-methylcatechol (1)

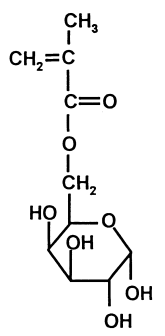

6-O-methacryloyl-D-galactose (2)

Fig. 1. Structures of Bz4MC, 1-Benzoyl-2-methacryloyloxyethyl-4-methylcatechol (1) and 6-O-Methacryloyl-D-galactose (2) 


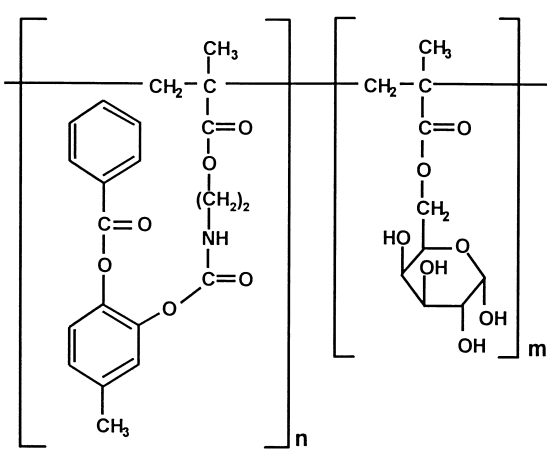

Poly I

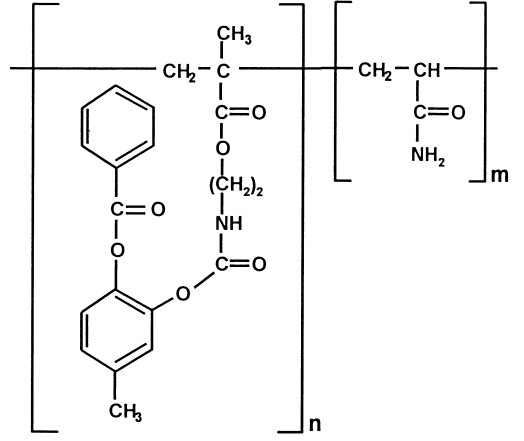

Poly II

Fig. 2. Structures of Poly I and II Prepared by Mechanochemical Solid-State Polymerization

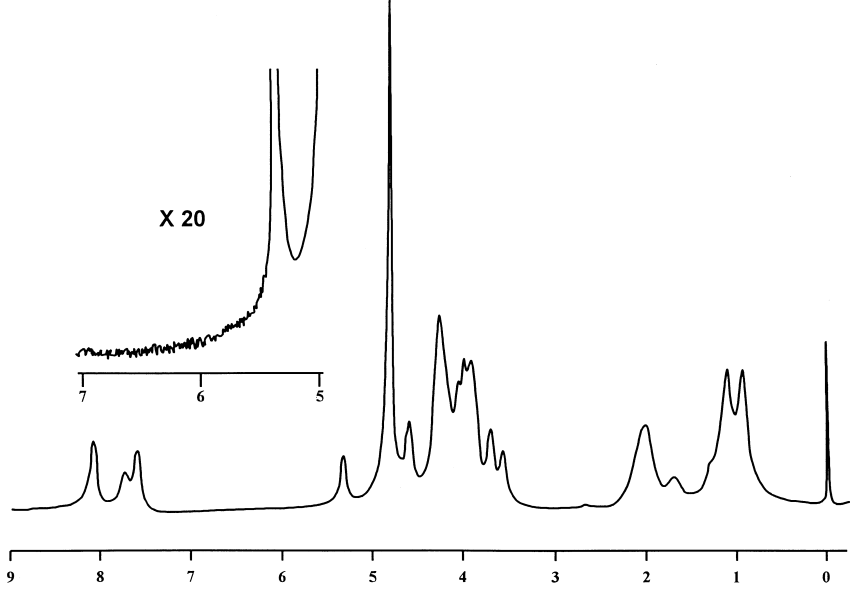

Chart 1. NMR Spectra of Poly I (0.1)

insoluble in water. On the other hand, Poly II (0.05) dissolved in water but the other Poly IIs, such as Poly II (0.1), were insoluble. The molecular weight of Poly I was similar to those of Poly II, and the number average molecular weight $\left(\bar{M}_{\mathrm{n}}\right)$ was $c a$. 30000 . These results suggest that monomer $\mathbf{2}$ is superior to AAm in terms of synthesis of water-soluble polymeric prodrug.

Table 1 shows the $\bar{M}_{\mathrm{n}}$ and heterogeneity $\left(\bar{M}_{\mathrm{w}} / \bar{M}_{\mathrm{n}}, \bar{M}_{\mathrm{w}}\right.$ is weight-average molecular weight) of Poly I. The value in the parentheses denotes the mole fraction of $\mathbf{1}$ in Poly I. The number average molecular weight was similar to one another. It was also shown that these polymeric prodrugs were of lower heterogeneity. In general, the polymer prepared by conventional radical-initiated solution polymerization possesses a broad molecular weight distribution, and its heterogeneity is more than 2 . The low heterogeneity is very important in nature due to avoiding the scatter of the behavior in the body and the rate of drug release of polymeric prodrugs by molecular weight.

Nature of Drug Release from Polymeric Prodrugs in Vitro Bz4MC is a hydrophobic compound and slightly soluble in water. We carried out the hydrolysis of Poly $\mathbf{I}$ in the mixture of acetonitrile and $\mathrm{pH} 7.4$ phosphate buffer solution $(1: 1)$ to prevent the saturation of Bz4MC.

Figure 3 shows the progressive changes in the concentration of Bz4MC and $4 \mathrm{MC}$ in the course of the hydrolysis of
Poly I. In the case of Poly I (0.1) the concentration of Bz4MC continues to increase for $c a .5 \mathrm{~h}$ and then tends to decrease toward $\mathrm{x}$-axis. The similar result was obtained for Poly I (0.05) and (0.2). The concentration of 4MC increased with increasing the reaction time. These results suggest that Bz4MC released was hydrolyzed to produce $4 \mathrm{MC}$. The total amount of Bz4MC released, area under the curve shown in Fig. 3, and the maximum concentration of $4 \mathrm{MC}$ indicated that the hydrolysis of a polymeric prodrug proceeded to completion.

Chart 2 shows the hydrolysis of Poly I and the subsequent reaction of Bz4MC. The rate constants of hydrolysis of polymeric prodrug and Bz4MC are defined as $k_{1}$ and $k_{2}$, respectively. Two rate equations are written

$$
\begin{aligned}
& -\mathrm{d}[\mathrm{P}] / \mathrm{d} t=k_{1}[\mathrm{P}] \\
& \mathrm{d}[\mathrm{D}] / \mathrm{d} t=k_{1}[\mathrm{P}]-k_{2}[\mathrm{D}]
\end{aligned}
$$

where $[\mathrm{P}]=$ amount of $\mathrm{Bz} 4 \mathrm{MC}$ bonded to the polymeric prodrug per unit volume at time $t$ and $[\mathrm{D}]=$ concentration of free Bz4MC at time $t$. These equations give

$$
[\mathrm{D}]=k_{1} P_{0}\left(\exp \left(-k_{1} t\right)-\exp \left(-k_{2} t\right)\right) /\left(k_{1}-k_{2}\right)
$$

where $P_{0}=$ total amount of Bz4MC in the polymeric prodrugs per unit volume at $t=0$.

The theoretical curves (solid curves) shown in Fig. 3 were obtained by fitting iteratively the rate constants, $k_{1}$ and $k_{2}$, with the obtained data of hydrolysis using a nonlinear leastsquares method. The values of the rate constants, $k_{1}$ and $k_{2}$, are listed in Table 2. The curve well fitted with the experimental data. It was shown that Eq. 3 and Chart 1 properly described the hydrolysis kinetics.

It was shown in Table 2 that the value of $k_{1}$ decreased with increasing the mole fraction of $\mathbf{1}$ in Poly $\mathbf{I}$. The value of $k_{2}$ was almost equal to one another. We separately examined the hydrolysis of Bz4MC under the same condition. The rate constant of the hydrolysis of Bz4MC was $0.110 \mathrm{~h}^{-1}$ and almost equal to the value of $k_{2}$ shown in Table 2. As shown in Table 1, the molecular weight and heterogeneity of Poly I were similar to one another. Therefore, the difference of the value of $k_{1}$ can be ascribed to the composition of polymeric prodrug, the mole fraction of $\mathbf{1}$. This result suggests that the rate constant of hydrolysis can be controlled by the mole fraction of $\mathbf{1}$. 

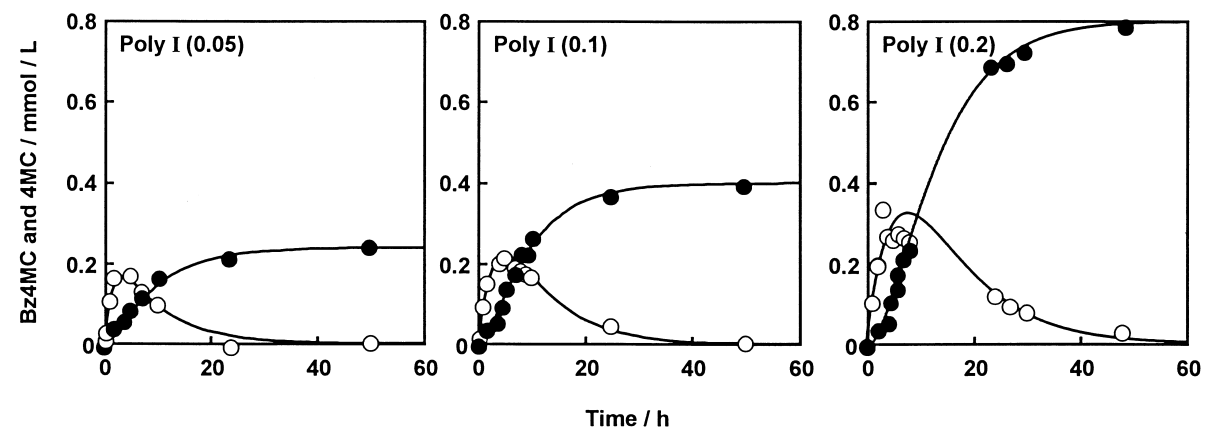

Fig. 3. Progressive Changes in the Concentration of Bz4MC $(\bigcirc)$ and $4 \mathrm{MC}(\mathbf{O})$ in the Course of Hydrolysis of Poly $\mathbf{I}$ in a Solution of a pH 7.4 Phosphate Buffer and Acetonitrile

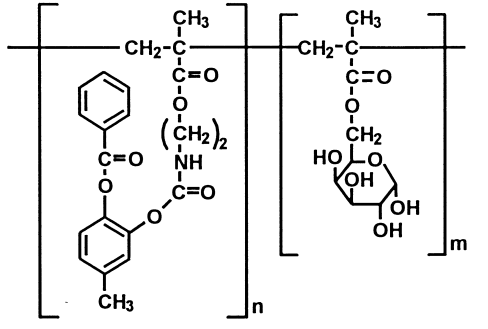

Poly I

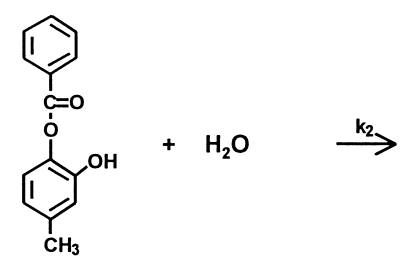

Bz4MC

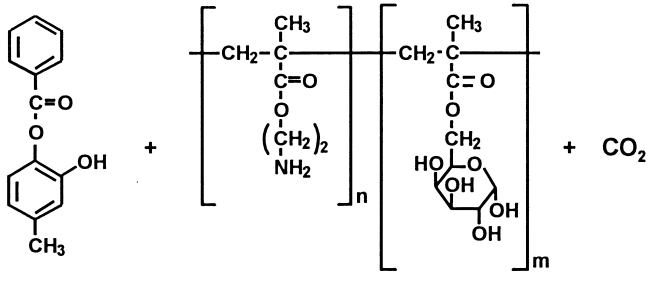

Bz4MC

Chart 2

Table 1. Molecular Weight and Heterogeneity of Poly I

\begin{tabular}{lcc}
\hline \hline Compound & $\begin{array}{c}\text { Number average molecular weight } \\
\left(\bar{M}_{\mathrm{n}}\right)\end{array}$ & $\begin{array}{c}\text { Heterogeneity } \\
\left(\bar{M}_{\mathrm{w}} / \bar{M}_{\mathrm{n}}\right)\end{array}$ \\
\hline Poly I (0.05) & 29000 & 1.16 \\
Poly I (0.1) & 28000 & 1.10 \\
Poly I (0.2) & 28000 & 1.10 \\
\hline
\end{tabular}

Table 2. Rate Constants of Hydrolysis Derived from Eq. 3

\begin{tabular}{lccc}
\hline \hline & $k_{1}\left(\mathrm{~h}^{-1}\right)$ & $k_{2}\left(\mathrm{~h}^{-1}\right)$ & Correlation coefficient \\
\hline Poly I (0.05) & 0.585 & 0.115 & 0.990 \\
Poly I (0.1) & 0.299 & 0.118 & 0.995 \\
Poly I (0.2) & 0.140 & 0.116 & 0.983 \\
\hline
\end{tabular}

\section{Conclusions}

The conclusion drawn from the present study can be summarized as follows: The benzoyl derivative of 4MC (Bz4MC) was selected as a model compound of $4 \mathrm{MC}$. We carried out the mechanochemical solid-state copolymerization of the vinyl monomer of Bz4MC with the hydrophilic vinyl monomer. The mechanochemical copolymerization proceeded to completion, and the polymeric prodrugs obtained possessed narrow molecular weight distributions (low heterogeneity). This feature is of great value for highly functionalized polymeric prodrug.

The hydrolysis of polymeric prodrug proceeded to completion. It was shown that Bz4MC released was further hydrolyzed under the present experimental condition to produce $4 \mathrm{MC}$. It can be suggested that the rate constant of hydrolysis could be controlled by the composition, the mole fraction of $\mathbf{1}$ in Poly $\mathbf{I}$. The correlationship between the rate constants of hydrolysis and copolymer structure (e.g. the composition and molecular weight) will be the subject of a forthcoming paper.

Acknowledgments This work is supported, in part, by Health Science Research Grant (Research on Brain Science) from the Ministry of Health and Welfare, which is greatly acknowledged.

\section{References}

1) Lapchak P. A., Exp. Neurol., 124, 16-20 (1993).

2) Olson, L., Exp. Neurol., 124, 5-15 (1993).

3) De Bernardi M. A., Fabrazzo M., Mocchetti I., "Neurotransmitter Regulation of Gene Transcription," ed. by Costa E., Joh T., Thieme N. Y., 1991, pp. 37-46.

4) Mocchetti I., Ann. Rev. Pharmacol. Toxicol., 32, 303-328 (1991).

5) Thoenen H., Zafra F., Hengerer B., Lindholm D., Ann. N.Y. Acad. Sci., 12, 86-90 (1991).

6) Schwartz J. P., Glia, 1, 282-285 (1988)

7) Furukawa Y., Tomioka N., Satoyoushi E., Hayashi K., Furukawa S., FEBS Lett., 247, 463-467 (1989). 
8) Follesa P., Mocchetti I., Mol. Pharmacol., 43, 132-138 (1992).

9) Carswell S., Exp. Neurol., 124, 36- 42 (1993).

10) Furukawa Y., Fukazawa N., Miyama Y. Hayashi K., Furukawa S., Biochem. Phamacol., 40, 2337-2342 (1991).

11) Carswell S., Hoffman E. K., Clopton-Hartpence K., Wilcox H. M., Lewis M. E., Mol. Brain Res., 15, 145-150 (1992).

12) Kaechi K., Furukawa Y., Idegami R., Nakamura N., Omae F., Hashimoto Y., Hayashi K., Furukawa S., J. Pharmacol. Exp. Ther., 264, 321-326 (1993).

13) Saporito M. S., Wilcox H. M., Hartpence K. C., Lewis M. E., Vaught J. L., Carswell S., Exp. Neurol., 123, 295-302 (1988).

14) Hanaoka Y., Ohi T., Furukawa S., Furukawa Y., Hayashi K., Matsukura S., J. Neurol. Sci., 122, 28-32 (1994).

15) Kourounakis A., Bodor N., Simpkins J., J. Pharm. Pharmacol., 49, $1-9$ (1997)

16) Glenner G. G., Med. Hypotheses, 5, 1231-1236 (1979).

17) Glenner G. G., Hum. Pathol., 16, 433- 435 (1985).

18) Eikelenboom P., Stam F. C., Virchows Arch. [B], 47, 17-25 (1984).

19) Powers J. M., Schlaepfer W. W., Willingham M. C., Hall B. J., J. Neuropathol. Exp. Neurol., 40, 592-612 (1981).

20) Probst A., Heitz P. U., Ulrich J., Virchows Arch. [A], 388, 327-334 (1980).

21) Kuzuya M., Kondo S., Noguchi A., Noda N., J. Polym. Sci., Polym. Chem., 29, 489-494 (1991).
22) Kuzuya M., Kondo S., Noguchi A., Macromolecules, 24, 4047-4053 (1991).

23) Kuzuya M., Kondo S., Chem. Pharm. Bull., 39, 3018-3022 (1991).

24) Kuzuya M., Kondo S., Murase K., J. Phys. Chem., 97, 7800-7802 (1993).

25) Kondo S., Murase K., Kuzuya M., Chem. Pharm. Bull., 42, 768-773 (1994).

26) Kondo S., Murase K., Kuzuya M., Chem. Pharm. Bull., 42, 24122417 (1994)

27) Kondo S., Kuzuya M., DDS, 9, 315-323 (1994).

28) Kuzuya M., Kondo S., "Polymeric Materials Encyclopedia," ed. by Salamone J. C., CRC Press Inc., Boca Raton, 1996, pp. 552-557.

29) Kondo S., Hosaka S., Kuzuya M., DDS, 12, 101-106 (1997).

30) Kondo S., Hosaka S., Kuzuya M., Chem. Pharm. Bull., 46, 669-673 (1998).

31) Kondo S., Hosaka S., Hatakeyama I., Kuzuya M., Chem. Pharm. Bull., 46, 1918-1923 (1998).

32) Kondo S., Hatakeyama I., Hosaka S., Kuzuya M., Chem. Pharm. Bull., 48, 1882-1885 (2000).

33) Kondo S., Yakugaku Zasshi, 120, 1337-1346 (2000).

34) Cosgrove S. L., Waters W. A., J. Chem. Soc., 1949, 3189-3194 (1949).

35) Schmit O. T., Methods Carbohydrate Chem., 2, 318-325 (1963). 